\title{
Sleep Quality in Schizophrenia
}

\author{
Aman Dule ${ }^{1 *}$, Gutema Ahmed ${ }^{2}$, Worknesh Tessema ${ }^{2}$, Matiwos Soboka ${ }^{2}$ \\ 'Mettu University, College of health science, Department of psychiatry, Mettu, Ethiopia \\ ${ }^{2}$ Jimma University, Institute of health science, Faculty of medicine, Department of psychiatry, Jimma, Ethiopia
}

\section{Article Info}

\section{Article Notes}

Received: November 7, 2020

Accepted: December 5, 2020

\section{*Correspondence:}

Mr. Aman Dule, M.Sc, Mettu University, College of Health Science, Department of Psychiatry, Mettu, Ethiopia; Telephone No: +251911418771; Email: amandule1993@gmail.com.

(c) 2020 Dule A. This article is distributed under the terms of the Creative Commons Attribution 4.0 International License.

\section{Keywords:}

Schizophrenia

Sleep quality

Khat use

Treatment adherence

\section{Abstract}

Purpose: The aim of this study is to assess the quality of sleep and contributing factors in treated patients with schophrenia.

Materials and methods: The sleep quality of 411 subjects in treatment for schizophrenia was assessed. A cross-sectional study design was used to determine mediating factors. A consecutive sampling technique was used for recruitment. The Pittsburgh Sleep Quality Index (PSQI) was used to assess outcome variables, and the positive and negative syndrome scale (PANSS) and the four-item Morisky-Green test (MGT) was used for symptom severity and medication adherence. Logistic regression analysis was used to determine factor association and the adjusted odds ratio (AOR) and a p-value $<0.05$ determined statistical significance.

Results: More than half of the patients were poor sleepers. Sleep determinants were: a) urban residence $A O R=3.08[2.57,8.12]$, b) family size $\geq 6$ AOR=2.72 $[1.38,5.08]$, c) current khat use $A O R=2.30[1.22,4.31]$, d) low antipsychotics adherence $A O R=6.23[3.61,10.75]$, e) positive and negative syndrome scale (PANSS) for positive symptoms greater than mean AOR=2.99 $[1.69,5.30]$ and PANSS for general symptoms greater than mean $A O R=4.22$ $[2.22,8.05]$. These were all significantly associated with sleep quality on multiple logistic regressions.

Conclusion: There is a high prevalence of poor sleep quality among schizophrenia patients and risk factors are known. It is time to address these factors clinically to ensure better health for this population.

\section{Introduction}

Schizophrenia is persistent and disabling psychotic illness that ruins the lives of patients and their families. It affects emotion, behavior, perception and sleep disturbances among others although these symptoms are not specific to schizophrenia ${ }^{1}$. Schizophrenia contributes 13.4 million years of life lived with disability (YLDs) to burden of disease globally and affects about $0.5 \%$ of people in Ethiopia ${ }^{2,3}$.

Sleep is the state of temporary decreased awareness of environmental stimuli and characterized by relative unconsciousness of the external world. It is a biological process which is crucial to the maintenance of mental and physical health. Sleep quality is satisfaction with sleep experience and integrating aspects of sleep initiation sleep maintenance, sleep quantity and refreshment upon awakening which is relevant to optimal health and functioning ${ }^{4}$. People with schizophrenia have been identified to experience sleep disorders at relatively higher rates than general population and sleep problems including difficulty falling asleep and maintaining it are common in these subjects ${ }^{5}$. 
Sleep is a restorative process for homeostasis regulation and helps for proper physiological functioning; so it is very important to maintain good physical, mental and emotional health. Short sleep duration (generally less than 7 hours) reported as an important risk factor for different adverse outcomes and can raises rates of mortality and national sleep foundation (NSF) has recommended optimal daily sleep durations for different age groups ${ }^{6,7}$. Decreased and non-restorative sleep is common complaints among people with mental illness and affects up to $30-80 \%$ of schizophrenic patients and repeated disturbance of sleep cycle or failure to initiate or maintain sleep can cause physical, mental, and emotional fatigue ${ }^{8}$.

Poor sleep in schizophrenia can precede psychotic onset in new patients and associated with treatment refractory deficits, chronic medical illness, poor mental health, accident and mortality ${ }^{9,10}$. Sleep problem can causes high economic burden; for instance, insomnia alone affects about 25 million people in United States and leads to a burden of 100 billion dollar annually shows that, the cost of not treating insomnia is greater than the cost of treating it $^{11}$.

The literatures also showed as poor sleep quality is associated with lower quality of life, suicidal behaviors and sometimes the disturbance even cause symptoms like paranoia ${ }^{12,13}$ and patients with sleep disturbances of all types were about 13 folds more likely to have suicidal ideation, suicide attempts and completed suicide than those without sleep disturbances ${ }^{14}$. It is reported as the sleep problem in psychiatric patients varies from $60 \%$ among newly referred to $91 \%$ of hospitalized patients in general and in schizophrenic patients, sleep disturbances affects up to $80 \%$ of the subjects ${ }^{15,16}$.

The studies showed that socio-economic characteristics like lower educational status, low income, living in large families and rural residence are positively associated with poor sleep quality and women had longer total sleep time, higher sleep efficiency and shorter sleep latency. On the other hand, insomnia was most prevalent in subjects aged 60 years and above, widowed and unemployed schizophrenic patients ${ }^{17-20}$. It is reported as there was the substantial difference in sleep quality between schizophrenic patients with predominant positive and negative psychotic symptoms in which patients with positive symptoms reported poorer sleep quality ${ }^{21}$.

Falling asleep and maintenance, daytime excessive sleepiness, poor sleep quality and deficiency in slow-wave sleep were highly prevalent in patients with psychiatric illness and these sleep disturbances can predict additional symptoms like depression ${ }^{17,22}$.

To our best knowledge, no the same study was found in our country previously and the current study was aimed to evaluate sleep quality and contributing factors among schizophrenic patients on follow-up treatment. Beside use as a base-line for future studies, it will help policy makers and care providers to give evidence based services.

\section{Material and Methods}

\section{Study design study area}

The current study was conducted as cross-sectional study at psychiatric clinic of Jimma University Medical Center among 411 schizophrenic patients who were on follow-up treatment.

\section{Inclusion and exclusion criteria}

We had included all patients who availed during data collection for follow-up treatment and those aged 18 and above to get independent informed consent. Patients with other psychiatric disorders comorbidity, those unable to communicate well, those who were at acute exacerbation of illness, and those who can't give written consent were excluded from the study. We had excluded patients with other psychiatric comorbidities because we intended to evaluate sleep pattern in schizophrenic patients exclusively since the sleep profile is different among different disorders from the literatures.

\section{Sample size and sampling techniques}

The minimum sample size was determined by single population proportion formula considering the following assumptions:

$$
\mathrm{n}=\frac{\left(z_{\alpha / 2}\right)^{2} \mathrm{p}(1-\mathrm{p})}{\mathrm{d}^{2}}
$$

Where, $\quad \mathbf{n}=$ minimum sample size required

$\mathrm{Z}_{\alpha / 2=}$ standard score value for $95 \%$ confidence level $=1.96$

$\mathrm{P}=$ Estimated prevalence for status of sleep quality in schizophrenic patients (taken 50\% since no published material is found in our country among the same subjects as far as searched).

\section{$\mathrm{d}=$ is margin of error $(5 \%)$}

Using the above assumptions and adding $10 \%$ of nonrespondent, the final sample size was $(384+38)=422$.

To get the intended sample size, all participants fulfill inclusion criteria were included according to their presence until the sample size achieved by using consecutive sampling technique.

\section{Study Variables}

The status of sleep quality (either good or poor) was considered out-comevariable forcurrentstudy. Independent variables like socio-demographic characteristics, current use of psycho-active substances (tobacco, alcohol and 
khat), comorbid physical illness, current antipsychotic medication/s, antipsychotics medication adherence status and severity of psychotic symptoms were evaluated.

\section{Data collection instruments and procedures}

Sleep quality was assessed by Pittsburgh Sleep Quality Index (PSQI) which differentiates "poor sleep" from "good sleep" by measuring seven domains: sleep duration, sleep disturbances, and sleep latency, use of sleep medication, daytime dysfunction, habitual sleep efficiency and subjective sleep quality over the last month. Scoring is based on Likert scale of 0 to 3 in which higher score indicates worse sleep quality and in this study; cut off point of 5 was used ${ }^{23}$. The tool was validated in Ethiopian adult community and has good psychometric validity and moderate internal consistency (Cronbach's alpha was 0.59). Internal homogeneity was sufficient as indicated by correlation coefficient between the scores of individual components and global score of the tool. With the cut-off scores of 5.5 , the tool's sensitivity was $82 \%$ and its specificity was $56.2 \%{ }^{24}$.

The severity of positive, negative and cognitive (general psychopathology) symptoms of schizophrenia was measured by using Positive and negative syndrome scale (PANSS) which is highly usable tool in patients with schizophrenia. It is 7-point rating instrument and contains 30-items grouped into P1-P7, N1-N7 and G1-G16 and high score indicates more severe psychotic symptoms ${ }^{25}$.

Antipsychotics medication adherence was measured by Morisky-Green test (MGT) ${ }^{26}$. It has four items to classify status of medication adherence as high, medium and low although it is dichotomized to high and low medication adherence as per the previous study in current study areas. Patients were assessed for current and ever use of psycho-active substance. Diagnosis, duration of the treatment, current antipsychotic medications, and absence/presence of any diagnosed physical illness were reviewed from the patient medical card. Data was collected by face to face interview using structured and pretested questionnaires and data was collected by four trained $\mathrm{BSc}$ junior psychiatry professionals.

\section{Data analysis}

Collected data were entered into Epi data version 3.1 (EpiData; Jens Lauritsen; Denmark) and analyzed by Statistical Package for Social Science (SPSS) version 23.0 (SPSS Inc; University of Stanford; USA). Chi-square test was used to compare status of sleep quality between categorical variables. Binary logistic regression was used to assess association of independent and outcome variables. Variables which has $\mathrm{p}<0.25$ were taken to multiple logistic regression. Collinearity diagnosis was assessed to test for confounders and the maximum value on variance inflation test was 2.7. Hosmer and Lameshow model fitness was checked and to decide statistically significant association, adjusted odd ratio, 95\% confidence interval and p-value < 0.05 were used.

\section{Results}

Finally, 411 were included in data analysis giving $97.4 \%$ of response rate. Majority of the participants were male and $74 \%$ of them were living with five or less family members. Most of them had no co-morbid physical illness and currently $19.2 \%, 14.4 \%$ and $34.1 \%$ were using tobacco, alcohol and khat respectively. Nearly, half of the participants were reported high adherence to antipsychotic medications and the mean score for positive scale of PANSS was $15.4 \pm$ SD 9.1; whereas, it is somewhat lower for negative scale $(11 \pm 4.4)$. Table 1 showed characteristics of study participants.

Greater proportion of male participants had reported poor sleep quality almost half of the poor sleepers were current khat users. More than two third of poor sleepers were low adherent to antipsychotic medications and majority of them had scored greater than mean for positive scale of PANSS. On the other hands, to see the difference in mean score of individual components of PSQI mean and standard deviation was calculated. Accordingly, no significant difference was observed for poor and good sleepers on individual score of this scale (Table 2).

Table 1: Characteristics of schizophrenic patients on follow-up treatment at Jimma University Medical Center, $2019(n=411)$

\begin{tabular}{|c|c|c|}
\hline Variables & Category & Frequency (\%) \\
\hline \multirow{2}{*}{ Age } & $18-44$ & $228(55.5)$ \\
\hline & $45-64$ & $183(44.5)$ \\
\hline \multirow{2}{*}{ Sex } & Male & $290(70.6)$ \\
\hline & Female & $121(29.4)$ \\
\hline \multirow{2}{*}{ Place of residence } & Urban & 203 (49.4) \\
\hline & Rural & $208(50.6)$ \\
\hline \multirow{2}{*}{ Family size } & $\leq 5$ & $305(74.2)$ \\
\hline & $\geq 6$ & $106(25.8)$ \\
\hline \multirow{2}{*}{ Physical illness } & Yes & $52(12.7)$ \\
\hline & No & $359(87.3)$ \\
\hline \multirow{2}{*}{ Current use of tobacco } & Yes & $79(19.2)$ \\
\hline & No & $332(80.8)$ \\
\hline \multirow{2}{*}{ Current use of alcohol } & Yes & $59(14.4)$ \\
\hline & No & $352(85.6)$ \\
\hline \multirow{2}{*}{ Current use khat } & Yes & $140(34.1)$ \\
\hline & No & 271 (65.9) \\
\hline \multirow{3}{*}{ Antipsychotic adherence } & High & 201 (48.9) \\
\hline & Low & $210(51.1)$ \\
\hline & \multicolumn{2}{|c|}{$M \pm S D$} \\
\hline PANSS positive score & \multicolumn{2}{|c|}{$15.4 \pm 9.1$} \\
\hline PANSS negative score & \multicolumn{2}{|c|}{$11 \pm 4.4$} \\
\hline
\end{tabular}

Note: Abbreviations

PANSS - Positive and negative syndrome scale

M - Mean

SD - Standard deviation 
Table 2: Characteristics of schizophrenic patients with good and poor sleep quality at Jimma University Medical Center, 2019

\begin{tabular}{|c|c|c|c|}
\hline \multirow{2}{*}{ Variables } & \multirow{2}{*}{ Category } & Participants with Good sleep quality ( $n=175)$ & \multirow{2}{*}{$\begin{array}{c}\text { Participants with poor sleep quality }(n=236) \\
\text { Frequency (\%) }\end{array}$} \\
\hline & & Frequency (\%) & \\
\hline Age & $\begin{array}{l}18-44 \\
45-64\end{array}$ & $\begin{array}{c}104(59.4) \\
71(40.6)\end{array}$ & $\begin{array}{l}114(48.3) \\
122(51.7)\end{array}$ \\
\hline Sex & $\begin{array}{l}\text { Male } \\
\text { Female }\end{array}$ & $\begin{array}{l}127(72.6) \\
48(27.4)\end{array}$ & $\begin{array}{l}154(65.3) \\
82(35.7)\end{array}$ \\
\hline Place of residence & $\begin{array}{l}\text { Urban } \\
\text { Rural }\end{array}$ & $\begin{array}{c}59(33.7) \\
116(66.3)\end{array}$ & $\begin{array}{c}142(60.2) \\
94(39.8)\end{array}$ \\
\hline Family size & $\begin{array}{l}\leq 5 \\
\geq 6\end{array}$ & $\begin{array}{l}142(81.1) \\
33(18.9)\end{array}$ & $\begin{array}{l}158(66.9) \\
78(33.1)\end{array}$ \\
\hline Physical illness & $\begin{array}{l}\text { Yes } \\
\text { No }\end{array}$ & $\begin{array}{c}13(7.4) \\
162(92.6)\end{array}$ & $\begin{array}{c}45(16.6) \\
191(80.9)\end{array}$ \\
\hline Current use of tobacco & $\begin{array}{l}\text { Yes } \\
\text { No }\end{array}$ & $\begin{array}{l}22(12.6) \\
153(87.4)\end{array}$ & $\begin{array}{l}61(25.8) \\
175(74.2)\end{array}$ \\
\hline Current use of alcohol & $\begin{array}{l}\text { Yes } \\
\text { No }\end{array}$ & $\begin{array}{c}19(10.9) \\
156(89.1)\end{array}$ & $\begin{array}{l}45(19.1) \\
191(80.9)\end{array}$ \\
\hline Current use khat & $\begin{array}{l}\text { Yes } \\
\text { No }\end{array}$ & $\begin{array}{c}36(20.6) \\
139(79.4)\end{array}$ & $\begin{array}{l}109(46.2) \\
127(53.8)\end{array}$ \\
\hline Antipsychotic adherence & $\begin{array}{l}\text { High } \\
\text { Low }\end{array}$ & $\begin{array}{l}132(75.4) \\
43(24.6)\end{array}$ & $\begin{array}{c}72(30.5) \\
164(69.5)\end{array}$ \\
\hline Positive PANSS & $\begin{array}{l}\leq \text { mean } \\
>\text { mean }\end{array}$ & $\begin{array}{l}138(78.9) \\
37(21.1)\end{array}$ & $\begin{array}{l}115(48.8) \\
121(51.2)\end{array}$ \\
\hline Negative PANSS & $\begin{array}{l}\leq \text { mean } \\
>\text { mean }\end{array}$ & $\begin{array}{l}145(82.9) \\
30(17.1)\end{array}$ & $\begin{array}{l}101(48.7) \\
116(51.3)\end{array}$ \\
\hline General PANSS & $\begin{array}{l}\leq \text { mean } \\
>\text { mean }\end{array}$ & $\begin{array}{l}150(85.7) \\
25(14.3)\end{array}$ & $\begin{array}{l}111(47.0) \\
125(53.0)\end{array}$ \\
\hline \multicolumn{4}{|c|}{ PSQI score of the patients with good and poor sleep quality } \\
\hline Variables & & $M \pm S D$ & $M \pm S D$ \\
\hline $\begin{array}{l}\text { Subjective sleep quality } \\
\text { Sleep latency } \\
\text { Sleep duration } \\
\text { Sleep efficiency } \\
\text { Sleep disturbances } \\
\text { Sleep medications } \\
\text { Daytime dysfunction }\end{array}$ & & $\begin{array}{l}1.3 \pm 1.0 \\
1.5 \pm 1.2 \\
1.1 \pm 1.0 \\
1.2 \pm 1.1 \\
1.0 \pm 0.9 \\
0.8 \pm 0.9 \\
1.1 \pm 1.0\end{array}$ & $\begin{array}{l}1.2 \pm 1.0 \\
1.5 \pm 1.1 \\
1.0 \pm 1.0 \\
1.2 \pm 1.0 \\
1.0 \pm 0.8 \\
0.8 \pm 1.0 \\
1.0 \pm 1.0\end{array}$ \\
\hline
\end{tabular}

\section{Note: Abbreviations}

PANSS - Positive and negative syndrome scale

M - Mean

SD - Standard deviation

Most of the respondents from rural residence had reported good sleep quality only $20.6 \%$ of them were using khat currently. More than three fourth (75.4\%) of good sleepers were highly adherent to current medications and relatively scored low on PANSS scale. Table 2 below contained characteristics of study variables for participants with good sleep quality.

On PSQI score, more than half of the participants had poor sleep quality. Only 154 (37.5\%) of the participants had sleep duration more than seven hours and $71.8 \%$ of them had reported sleep disturbances in general. (Table 3)

\section{Factors associated with sleep quality}

To identify variables associated with sleep quality, p-value $<0.25$ on univariate analysis was considered for significance association. Accordingly, age of participants, residence, family size, comorbid physical illness, current substance use (tobacco, alcohol and khat), antipsychotic medications adherence and PANSS score were significantly associated on univariate analysis.

After adjusting for potential confounders using multivariate analysis, the odds of poor sleep quality for urban respondents was about three times (AOR $=3.01$, $95 \%$ CI: 2.57-8.12) higher than respondents from rural residence and respondents who were living with $\geq 6$ family members had about two times (AOR $=2.72$, $95 \%$ CI: 1.38 5.08 ) odds than those living with $\leq 5$ family members. The odds of poor sleep quality was doubled (AOR=2.30, $95 \%$ CI: 1.22-4.31) for current khat users when compared to non-users and low adherent patients had about six times $(A O R=6.23,95 \%$ CI: 3.61-10.75) higher odds for poor sleep quality. 
Table 3: Score on PSQI for schizophrenic patients on follow-up treatment at Jimma University Medical Center, 2019 ( $n=411)$

\begin{tabular}{|l|c|c|}
\hline \multicolumn{1}{|c|}{ Variables } & Category & Frequency (\%) \\
\hline \multirow{3}{*}{ Subjective sleep quality } & Very good & $109(26.5)$ \\
& Fairly good & $147(35.8)$ \\
& Fairly bad & $95(23.1)$ \\
& Very bad & $60(14.6)$ \\
\hline \multirow{3}{*}{ Sleep latency } & Very good & $100(24.3)$ \\
& Fairly good & $122(29.7)$ \\
\hline \multirow{3}{*}{ Sleep duration } & Fairly bad & $82(20.0)$ \\
& Very bad & $107(26.0)$ \\
\hline \multirow{3}{*}{ Sleep efficiency } & $>7$ hours & $154(37.5)$ \\
& $6-7$ hours & $142(34.5)$ \\
\hline \multirow{2}{*}{ Sleep disturbance } & $5-6$ hours & $66(16.1)$ \\
& $<5$ hours & $49(11.9)$ \\
\hline \multirow{2}{*}{ Use of sleep medication } & $>85 \%$ & $134(32.6)$ \\
\hline \multirow{2}{*}{ Global PSQI score } & $75-84 \%$ & $131(31.9)$ \\
& $65-74 \%$ & $79(19.2)$ \\
& $<65 \%$ & $67(16.3)$ \\
\hline & Yes & $295(71.8)$ \\
& Poor sleep quality & $116(28.2)$ \\
\hline & Good sleep quality & $175(42.6)$ \\
\hline
\end{tabular}

Participants who had scored greater than mean on PANSS positive and general scales had higher odds for poor sleep when compared to those scored $\leq$ mean as shown in table 4 .

\section{Discussion}

In the current study, more than half of the patients (57.4\%) with 95\%CI: [52\%-62\%] were reported poor sleep quality which is in agreement with different previous studies which had reported high prevalence of poor sleep quality $^{27-29}$. The current finding was higher than the other studies done before probably because of different study settings and study years, duration of the illness, tools used to assess sleep quality and inclusion criteria of the study participants $^{30-32}$.

Although no significant association was found between sleep quality and age in current result, the study done in China and Turkey had reported as advanced age and ages between 15-21 were significantly associated with poor sleep quality respectively ${ }^{17,33}$.

In current study, respondents who were living with $\geq 6$ family members were more likely to had poor sleep quality than those who were living with five or less family members. This might be evidenced by the difference in individual behaviors and sleep timing which can make imbalance and disturb sleep. This finding was in line with the study done in Ghana in which major proportion of respondents from large families had reported more sleep disturbances and other supportive study from USA which revealed that participants living with $\geq 3$ children had reported frequent insufficient and poor sleep quality ${ }^{20,34}$.
In this study, participants with the history of current Khat use were more likely to had poor sleep quality. This can be evidenced by the fact that khat has stimulant effects that can increase sleep latency and in turn contribute for poor quality of sleep. The study done in Yale university supports this finding in which both stimulants and depressants had significantly contribute to worse sleep quality by decreasing sleep time and increasing sleep latency ${ }^{35}$.

The Odenwald $M$. also reported similar finding in which khat chewing was significantly associated with poor sleeping and psychotic symptoms severity and similarly, the study done in Jimma town community also reported as khat chewing has significance association with poor sleep quality ${ }^{36,37}$.

As the findings of current study implies, respondents who were scored greater than mean for PANSS positive and general scales had greater odds of poor sleep quality than those who scored less than/equal to mean on the same scales. This finding can be justified by that positive psychotic symptoms like hallucinations and delusions can made the patients feel fear and fall asleep more slowly which can contribute for bad sleep in these patients. In other cases, presence of other overall psychopathology like anxiety and depressive symptoms can cause persistent nightmares which can highly affect sleep quality ${ }^{16}$. Current finding was agrees with the study done in Iran in which positive psychotic symptoms were significantly associated with disturbed sleep, higher impairments of daily functioning and poorer sleep quality and the study done in Oxford which was reported as hallucination and paranoia had significantly associated with sleep disturbances and poor sleep quality ${ }^{38,39}$. Although current study identified as positive psychotics symptoms significantly associated with poor sleep quality, the study done in Portugal reported as no significant difference was observed between both patients with dominant positive and negative psychotic symptoms $^{40}$.

Using standard tools, evaluate outcome variables by culturally validated tool and high response rate can be taken as the strength for current study. However; some limitations were identified for this study: firstly- only subjective assessment of the patients was performed and objective measures like actigraphy and polysomnography was not performed so recall bias cannot be ruled out. Secondly- Sleep disorders were not ruled out and this can fluctuate current finding. Thirdly - some variables which considered have association with status of sleep quality such as occupation, physical activity, diet status and illness related stigma have not assessed which should be considered in future studies.

\section{Conclusions}

Generally, in current study we concluded as poor 
Table 4: Bivariate and multivariate logistic regression analysis of factors associated with sleep quality among schizophrenic patients on follow-up treatment at Jimma University Medical Center, 2019 ( $n=411)$

\begin{tabular}{|c|c|c|c|c|c|}
\hline \multirow{2}{*}{ Variables category } & \multicolumn{2}{|c|}{ Sleep quality } & \multirow{2}{*}{ COR (95 \% Cl) } & \multirow{2}{*}{ AOR $(95 \% \mathrm{Cl})$} & \multirow{2}{*}{ P-Value } \\
\hline & Good (\%) & Poor (\%) & & & \\
\hline $\begin{array}{l}\text { Age } \\
18-44 \\
45-64\end{array}$ & $\begin{array}{l}104(45.6) \\
71(38.8)\end{array}$ & $\begin{array}{l}124(54.4) \\
112(61.2)\end{array}$ & $\begin{array}{c}1.00 \\
0.76(0.51,1.12)\end{array}$ & $\begin{array}{c}1.00 \\
0.72(0.42,1.26)\end{array}$ & 0.25 \\
\hline $\begin{array}{l}\text { Residence } \\
\text { Rural } \\
\text { Urban }\end{array}$ & $\begin{array}{l}116(55.8) \\
59(29.1)\end{array}$ & $\begin{array}{c}92(44.2) \\
144(70.9)\end{array}$ & $\begin{array}{c}1.00 \\
4.67(2.05,4.63)\end{array}$ & $\begin{array}{c}1.00 \\
3.08(2.57,8.12)^{*}\end{array}$ & $<0.001$ \\
\hline $\begin{array}{l}\text { Family size } \\
\leq 5 \\
\geq 6\end{array}$ & $\begin{array}{l}149(48.9) \\
26(24.5)\end{array}$ & $\begin{array}{l}156(51.1) \\
80(75.5)\end{array}$ & $\begin{array}{c}1.00 \\
3.92(1.79,4.83)\end{array}$ & $\begin{array}{c}1.00 \\
2.72(1.38,5.08)^{*}\end{array}$ & $<0.001$ \\
\hline $\begin{array}{l}\text { Physical illness } \\
\text { No } \\
\text { Yes }\end{array}$ & $\begin{array}{c}164(45.7) \\
11(21.2)\end{array}$ & $\begin{array}{l}195(54.3) \\
41(78.8)\end{array}$ & $\begin{array}{c}1.00 \\
2.47(1.27,4.78)\end{array}$ & $\begin{array}{c}1.00 \\
2.23(0.89,5.53)\end{array}$ & 0.09 \\
\hline $\begin{array}{l}\text { Tobacco use a } \\
\text { No } \\
\text { Yes }\end{array}$ & $\begin{array}{l}153(46.1) \\
22(27.8)\end{array}$ & $\begin{array}{l}179(53.9) \\
57(72.2)\end{array}$ & $\begin{array}{c}1.00 \\
2.22(1.29,3.79)\end{array}$ & $\begin{array}{c}1.00 \\
0.69(0.22,2.14)\end{array}$ & 0.52 \\
\hline $\begin{array}{l}\text { Alcohol use a } \\
\text { No } \\
\text { Yes }\end{array}$ & $\begin{array}{l}156(44.3) \\
19(32.2)\end{array}$ & $\begin{array}{l}196(55.7) \\
40(67.8)\end{array}$ & $\begin{array}{c}1.00 \\
1.68(0.93,3.01)\end{array}$ & $\begin{array}{c}1.00 \\
0.73(0.21,2.54)\end{array}$ & 0.62 \\
\hline $\begin{array}{l}\text { Current khat use } \\
\text { No } \\
\text { Yes }\end{array}$ & $\begin{array}{l}139(51.3) \\
36(25.7)\end{array}$ & $\begin{array}{l}132(48.7) \\
104(74.3)\end{array}$ & $\begin{array}{c}1.00 \\
3.04(1.94,4.76)\end{array}$ & $\begin{array}{c}1.00 \\
2.30(1.22,4.31)^{*}\end{array}$ & 0.01 \\
\hline $\begin{array}{l}\text { Adherence } \\
\text { High } \\
\text { Low }\end{array}$ & $\begin{array}{l}132(65.7) \\
43(20.5)\end{array}$ & $\begin{array}{c}69(34.3) \\
167(79.5)\end{array}$ & $\begin{array}{c}1.00 \\
7.43(4.77,11.58)\end{array}$ & $\begin{array}{c}1.00 \\
6.23(3.61,10.75)^{*}\end{array}$ & $<0.001$ \\
\hline $\begin{array}{l}\text { PANSS Positive } \\
\leq \text { mean } \\
>\text { mean }\end{array}$ & $\begin{array}{l}150(60.2) \\
25(15.4)\end{array}$ & $\begin{array}{c}99(39.8) \\
137(84.6)\end{array}$ & $\begin{array}{c}1.00 \\
4.27(2.74,6.66)\end{array}$ & $\begin{array}{c}1.00 \\
2.99(1.69,5.30)^{*}\end{array}$ & $<0.001$ \\
\hline $\begin{array}{l}\text { PANSS Negative } \\
\leq \text { mean } \\
\text { >mean }\end{array}$ & $\begin{array}{c}145(55.3) \\
30(20.1)\end{array}$ & $\begin{array}{l}117(44.7) \\
119(79.9)\end{array}$ & $\begin{array}{c}1.00 \\
4.92(3.08,7.86)\end{array}$ & $\begin{array}{c}1.00 \\
1.90(1.00,3.63)\end{array}$ & 0.05 \\
\hline $\begin{array}{l}\text { PANSS General } \\
\leq \text { mean } \\
>\text { mean }\end{array}$ & $\begin{array}{l}150(58.6) \\
25(16.1)\end{array}$ & $\begin{array}{l}106(41.4) \\
130(83.9)\end{array}$ & $\begin{array}{c}1.00 \\
7.36(4.49,12.07)\end{array}$ & $\begin{array}{c}1.00 \\
4.22(2.22,8.05)^{*}\end{array}$ & $<0.001$ \\
\hline
\end{tabular}

Abbreviations: COR - Crude Odd Ratio

Cl-Confidence interval a- current use

AOR - Adjusted Odd Ratio

Significant association ( $p$-value $<0.05$ )

sleep quality is high among people with schizophrenia and accordingly we recommended to health care givers to give due attention to sleep assessment while treating schizophrenic patients and it could be better for Jimma University Medical Center to employ sleep laboratory to provide comprehensive care.

\section{Abbreviations}

MGT - Morisky-Green test

NSF - National sleep foundation

PANSS - Positive and negative syndrome scale

PSQI - Pittsburgh Sleep Quality Index

SD - Standard deviation

USA - United states of America

\section{Ethics Approval and Informed Consent}

Written consent was taken from all study participants and ethical clearance was obtained from the ethical review board of Jimma University Institute of health and research protocol was done accordance with declaration of Helsinki and all the ethical regulations stated by research ethical committee of the University was followed. No any invasive procedure was done and all information from the patients was kept confidential.

\section{Authors' Contributions}

All authors made substantial contributions to conception and design, acquisition of data or analysis and interpretation of data; took part in drafting the article or revising it critically for important intellectual content and gave final approval of version to be published. 


\section{Acknowledgment}

We would like to extend our gratitude to Mettu University to funding us and Jimma University medical center psychiatric clinic staffs for their great cooperation and all study participants.

\section{Funding}

The financial need for data collection in this study was completed by Mettu University, but the funding did not include publication processing fee. Apart from this, the organization has no any role in any stage of the paper from study design to submission for publication.

\section{References}

1. Benjamin James Sadock MD, Virginia Alcott Sadock MD, Pedro Ruiz MD. Synopsis of Psychiatry Behavioral Sciences/Clinical Psychiatry, 11th edt. 11th editi. Caroly S. Pataki NS, editor. APA. 2015; 649-652.

2. Baron EC, Rathod SD, Hanlon C, et al. Impact of district mental health care plans on symptom severity and functioning of patients with priority mental health conditions: the Programme for Improving Mental Health Care (PRIME) cohort protocol Emily. BMC Psychiatry. 2018; 18(61): 1-15.

3. Republic FD. Federal Democratic Republic of Ethiopia Ministry of Health NATIONAL MENTAL. 2015; 11.

4. Pritchett D, Wulff K, Oliver PL. Evaluating the links between schizophrenia and sleep and circadian rhythm disruption. J Neural Transm. 2012; 119: 1061-75.

5. Afonso P, Brissos S, Bobes J, et al. Personal and social functioning and satisfaction with life in schizophrenia outpatients with and without sleep disturbances. J Ment Heal. 2015; 1(1): 33-40.

6. Fang S, Suzuki K, Lim CL, et al. Associations between sleep quality and inflammatory markers in patients with schizophrenia. Psychiatry Res. 2016; 246: 154-60.

7. Müller MJ, Olschinski C, Kundermann B, et al. Subjective sleep quality and sleep duration of patients in a psychiatric hospital. Sleep Sci. 2016; 9(3): 202-6

8. Seun-fadipe CT, Psych M, Mosaku KS. Sleep quality and psychological distress among undergraduate students of a Nigerian university. Sleep Heal. 2017; 3: 190-4.

9. Ferrarelli F. Sleep in patients with schizophrenia. Curr Sleep Med Rep. 2016; 1(2): 150-6.

10. Karl Peltzer SP. Self-reported sleep duration and its correlates with sociodemographics, health behaviours, poor mental health, and chronic conditions in rural persons 40 years and older in South Africa. Int J Environ Res Public Heal. 2018; 15(1357): 1-9.

11. Khurshid KA. Comorbid Insomnia and Psychiatric Disorders: An Update. Innov Clin Neurosci. 2018; 15(3-4): 28-32.

12. Sarah Reeve, Bryony Sheaves DF. Sleep Disorders in Early Psychosis : Incidence, Severity, and Association With Clinical Symptoms. Schizophr Bull. 2019; 45(2): 287-95.

13. Koyanagi A, Stickley A. The Association between Sleep Problems and Psychotic Symptoms in the General Population: A Global Perspective. Sleep Sci. 2015; 38(12).

14. Sutton EL. Psychiatric disorders and sleep issues. Med Clin N Am. 2014; 98: 1123-43.

15. Niet G De, Tiemens B, Persona P, et al. Perceived sleep quality of psychiatric patients. J Psychiatr Ment Health Nurs. 2008; 15: 465-470
16. Ered A, Cooper S, Ellman LM. Sleep quality, psychological symptoms, and psychotic-like experiences. J Psychiatr Res. 2018; 98: 95-8.

17. Song G, Xu X, Tian T, et al. The Prevalence of Sleep Disturbance and Its Socio-demographic and Clinical Correlates in First-episode Individuals With Schizophrenia in Rural China. Perspect Psychiatr Care. 2018; 54: 31-8.

18. Lemola S, Ledermann T, Friedman EM. Variability of Sleep Duration Is Related to Subjective Sleep Quality and Subjective Well-Being: An Actigraphy Study. PLoS One. 2013; 8(8): 1-9.

19. Ogbolu RE, Aina OF, Famuyiwa O0, et al. A Study of Insomnia among Psychiatric Out-Patients in Lagos Nigeria. J Sleep Disord Ther. 2012; $1(4): 1-5$

20. Yaya S, Wang R, Shangfeng T, et al. Alcohol consumption and sleep deprivation among Ghanaian adults: Ghana Demographic and Health Survey. peer J. 2018; 6: 1-14.

21. Faezeh Tatari, Habibolah Khazaie PP. Sleep quality in patients with positive and negative symptoms of schizophrenia. Eur J Pers Centered Healthc. 2018; 6(2): 257-61.

22. Hombali A, Seow E, Yuan Q, et al. Prevalence and correlates of sleep disorder symptoms in psychiatric disorders. Psychiatry Res. 2019; 279(May 2018): 116-22.

23. Buysse DJ, Reynolds CF, Monk TH, et al. The Pittsburgh Sleep Quality Index (PSQI): A new instrument for psychiatric research and practice. Psychiatry Res. 1989; 28: 193-213.

24. Salahuddin M, Maru TT, Kumalo A, et al. Validation of the Pittsburgh sleep quality index in community dwelling Ethiopian adults. Health Qual Life Outcomes. 2017; 15(58): 1-7.

25. Santor DA, Ascher-svanum H, Lindenmayer J, et al. Item response analysis of the Positive and Negative Syndrome Scale. BMC Psychiatry. 2007; 7(66): 1471-244.

26. Morisky DE, Green LW, Levine DM. Concurrent and predictive validity of a self-reported measure of medication adherence. Med Care. 1986; 24(1): 67-74.

27. Mattai AA, Tossell J, Greenstein DK, et al. Sleep disturbances in childhood-onset schizophrenia. Schizophr Res. 2006; 86: 123-9.

28. Campos EDM, Melo CM, Maia WS, et al. Sleep disturbances and gender differences in schizophrenia. Sleep Sci. 2008; 1(9): 27-30.

29. Noort M Van Den, Struys E, Perriard B, et al. Schizophrenia and depression : The relation between sleep quality and working memory. AJP. 2016; 24: 73-8.

30. Xiang Y, Weng Y, Leung C, et al. Prevalence and Correlates of Insomnia and its Impact on Quality of Life in Chinese Schizophrenia Patients. Sleep. 2009; 32(1): 105-9.

31. Ritsner M, Kurs R, Ponizovsky A, et al. Perceived quality of life in schizophrenia: Relationships to sleep quality. Qual life Res. 2004; 13: 783-791.

32. Örsal Ö, Eren HK. Examination of factors affecting the sleep quality of psychiatry patients using structural equation model.J Psyciatric Nurs. 2019; 10(1): 55-64.

33. Med E, Investigation 0 . Sleep quality and factors affecting it in patients with chronic psychiatric disorders. Erciyes Med J. 2015; 37(1): 6-10.

34. Chapman DP, Wheaton AG, Croft JB. Household Demographics and Perceived Insufficient Sleep Among US adults. J Community Heal. 2012; 37(2): 344-9.

35. Angarita GA, Emadi N, Hodges S, et al. Sleep abnormalities associated with alcohol, cannabis, cocaine, and opiate use : a comprehensive review. Addict Sci Clin Pr. 2016; 11(9): 1-17.

36. Odenwald M. Chronic khat use and psychotic disorders: A review of the literature and future prospects. Sucht. 2014; 53(1): 9-22. 
37. Berhanu H, Mossie A, Tadesse S, et al. Prevalence and Associated Factors of Sleep Quality among Adults in Jimma Town, Southwest Ethiopia: A Community-Based Cross-Sectional Study. Sleep Disord. 2018; $1-10$.

38. Faezeh T, Habibolah K PP. Sleep quality in patients with positive and negative symptoms of schizophrenia Sleep quality in patients with positive and negative symptoms of schizophrenia. Eur J Pers Centered Healthc. 2018; 6(2): 257-61.
39. Reeve S, Emsley R, Sheaves B, et al. Disrupting Sleep: The Effects of Sleep Loss on Psychotic Experiences Tested in an Experimental Study With Mediation Analysis. Schizophr Bull. 2018; 44(3): 662-71.

40. Afonso P, Luísa M, Paiva T. Schizophrenia patients with predominantly positive symptoms have more disturbed sleep - wake cycles measured by actigraphy. Psychiatry Res. 2011; 189: 62-6. 